\title{
Vitamin D deficiency in patients with liver cirrhosis
}

\author{
Christos Konstantakis, Paraskevi Tselekouni, Maria Kalafateli, Christos Triantos
}

University Hospital of Patras, Patras, Greece

\section{Abstract}

\begin{abstract}
There is ongoing evidence that vitamin D is related to the pathophysiology of cirrhosis. Although the incidence of vitamin D deficiency in chronic liver diseases and cirrhosis is strongly documented, its pathogenic association with advanced liver fibrosis remains controversial. There is evidence of a significant relation of $25(\mathrm{OH}) \mathrm{D}$ levels with the degree of liver dysfunction, considering that an inverse correlation of 25(OH)D levels with both Child-Pugh score and Model for End-Stage Liver Disease has been reported. In addition, vitamin D deficiency has been shown to increase the risk for overall mortality and infections in patients with cirrhosis. Vitamin D deficiency has been also associated with advanced stages of hepatocellular carcinoma and poor prognosis. Finally, there are studies suggesting that patients with chronic hepatitis $\mathrm{C}$ and normal vitamin $\mathrm{D}$ levels have higher virological response to treatment. However, there are not enough studies conducted in cirrhoticonly populations. The association between vitamin $\mathrm{D}$ and cirrhosis demonstrates a great potential for clinical application. The relation between vitamin D deficiency and the degree of liver function, degree of fibrosis and infectious complications could support its use as a prognostic index and a diagnostic tool.
\end{abstract}

Keywords Vitamin D, vitamin D deficiency, vitamin D insufficiency, liver cirrhosis, prognosis

\section{Introduction}

Vitamin D is a secosteroid hormone, which is mostly known as a regulator of calcium and bone metabolism. However, vitamin D has pleiotropic effects including cellular proliferation, differentiation and immunomodulation [1]. These extra-skeletal effects have been related to the pathogenesis and treatment of infections, cardiovascular, autoimmune and degenerative diseases and several types of cancer [2].

The role of vitamin D in chronic liver diseases is not well known, but there are reports suggesting that this hormone has anti-inflammatory and anti-fibrotic effects and, consequently, it has a significant role in the natural history of chronic liver diseases, such as chronic hepatitis $\mathrm{C}$ and non-alcoholic fatty liver disease (NAFLD) [3]. The aim of this review was to assess vitamin $\mathrm{D}$ deficiency in patients with advanced liver fibrosis

Department of Gastroenterology, University Hospital of Patras, Patras, Greece

Conflict of Interest: Dr Triantos has received fees for serving as a speaker for Bristol-Myers Squibb and Gilead

Correspondence to: Christos Triantos, MD, Department of Gastroenterology, University Hospital of Patras, Stamatopoulou 4, Rio, Patras 26504 Greece, e-mail: chtriantos@hotmail.com

Received 16 July 2015; accepted 26 March 2016; published online 25 April 2016

DOI: http://dx.doi.org/10.20524/aog.2016.0037 and cirrhosis. We searched (CK, PT) Medline, Scopus and Google Scholar databases from November 1950 to May 2015 using the textwords: "vitamin D", "cirrhosis", "liver disease" and "deficiency" and abstracts from major Gastroenterology and Liver meetings.

\section{Vitamin D metabolism}

The basic metabolism of vitamin $\mathrm{D}$ has been extensively studied. Dietary sources [such as fatty fish, eggs and artificially fortified foods (oral supplements)] provide vitamin $\mathrm{D}_{2}$ and vitamin $\mathrm{D}_{3}$, absorbed in the intestine by biliary acids and then transported via chylomicrons to the circulation [4-6]. The main source of vitamin D is biosynthesis from epidermal cells as a result of exposure to sunlight. Initially, 7-dehydrocholesterol, a metabolite of cholesterol, is converted into pre-vitamin $\mathrm{D}_{3}$ by ultraviolet- $\mathrm{B}$ radiation in the lower epidermis. Then, previtamin $\mathrm{D}_{3}$ is transformed into vitamin $\mathrm{D}_{3}$ (cholecalciferol) in a heat-dependent process. A significant percentage of vitamin $\mathrm{D}_{3}$ is metabolized by sunlight and so the equilibrium between pre-vitamin $\mathrm{D}_{3}$ and vitamin $\mathrm{D}_{3}$ is maintained. Vitamin $\mathrm{D}$ that comes from dietary sources or skin synthesis can be stored in the adipocytes or it may undergo hepatic 25-hydroxylation [5]. Vitamin $\mathrm{D}_{3}$ is bound to vitamin D-binding protein (DBP) or albumin and it is transferred to the liver, where 25-hydroxylation takes place [4] (Fig. 1).

Eighty eight per cent of $25(\mathrm{OH}) \mathrm{D}$ is bound to DBP, a protein synthesized by the liver and a member of the albumin 


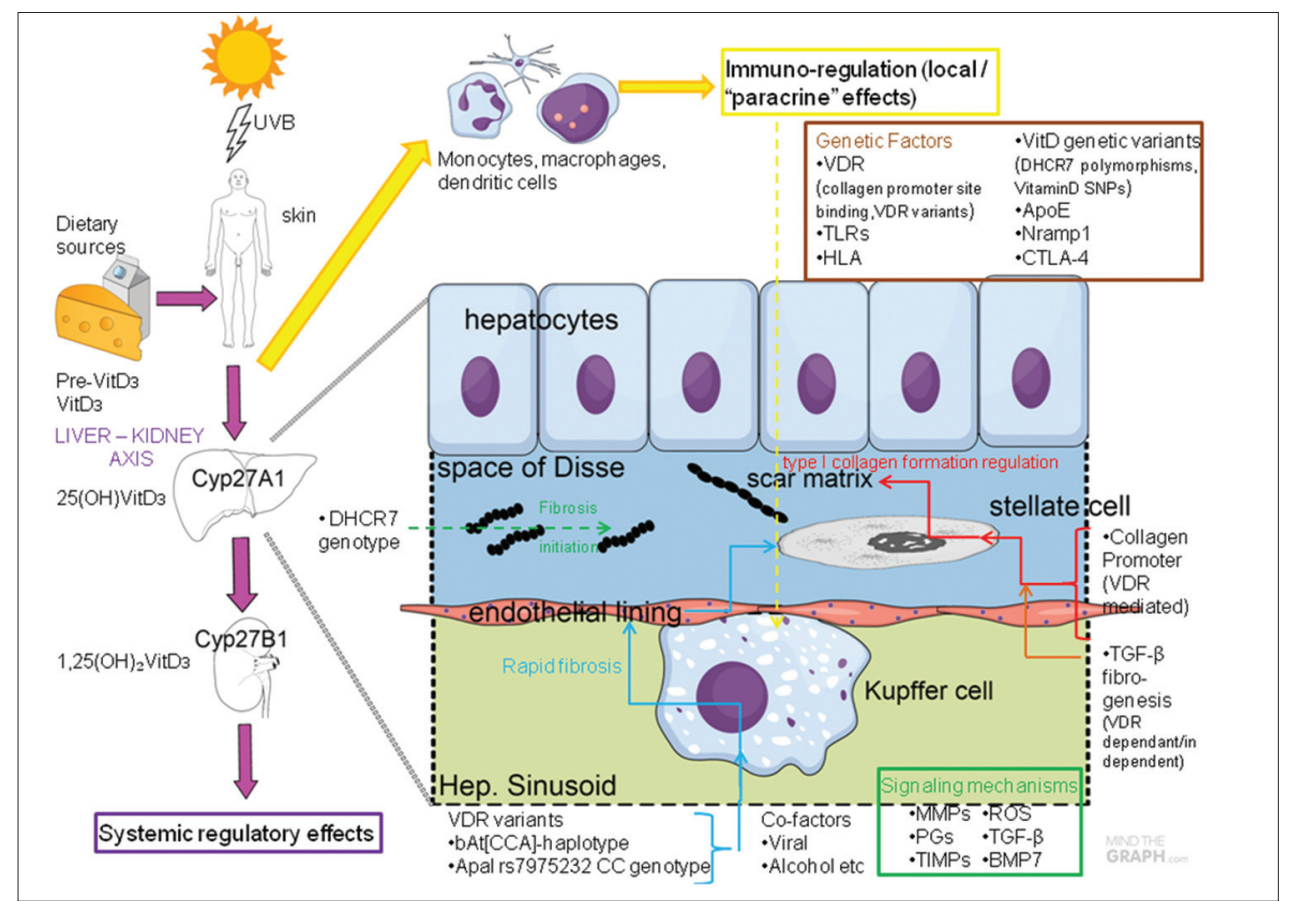

Figure 1 Vitamin $\mathrm{D}$ and liver fibrosis. Dietary sources provide vitamin $\mathrm{D}_{2}$ and vitamin $\mathrm{D}_{3}$, which are absorbed in the intestine. The main source of vitamin $\mathrm{D}$ is biosynthesis from epidermal cells as a result of exposure to sunlight. Vitamin $\mathrm{D}_{3}$ is transferred to the liver, where 25 -hydroxylation takes place. $25(\mathrm{OH}) \mathrm{D}$ is transported to the kidney where it is again enzymatically hydroxylated to form $1,25(\mathrm{OH}) \mathrm{D}_{3}$ or calcitriol (the active form of vitamin $\mathrm{D}_{3}$ ). Calcitriol through its receptor, VDR, exerts its systemic (endocrine - purple axis) regulatory effects on many different target organs. A second $1,25(\mathrm{OH}) \mathrm{D}_{3}$ pool is proposed (paracrine - yellow axis), that involves the immune system and the local production of calcitriol by immune cells, which could contribute to immune regulation

The complex interplay between environmental, genetic, cell signaling and other host factors that drive the inflammatory process and fibrogenesis remains a topic of research. "Key players" of this process are presented in this figure

- DHCR7 genotype / polymorphisms = The DHCR7 gene has been proposed to be able to affect vitamin D serum levels. A link with the severity of fibrosis has been suggest, namely with the (GG) homozygote of the DHCR7 gene. A stronger association of the susceptible DHCR7 SNPs (single nucleotide polymorphisms) with fibrosis initiation rather than progression has been suggested

- Collagen promoter $=$ There is evidence that $1,25-(\mathrm{OH}) 2 \mathrm{D}_{3}$ inhibits type I collagen formation in stellate cells, mainly by binding to specific sites. At least two sites have been identified, with the proximal Sp 1-1 site being the most recognizable

- $\quad V D R$ variants $=V D R$ polymorphisms have been associated with liver fibrosis

- Signaling mechanisms = A host of enzymes, growth factors and other physiologically active compounds are in complex interaction, resulting in the regulation of liver inflammation and fibrosis

UVB, ultraviolet B; VitD, vitamin D; Cyp27A1, cytochrome P450, family 27, subfamily A, polypeptide 1; Cyp27B1, cytochrome P450, family 27, subfamily B, polypeptide 1; VDR, vitamin D receptor; TLRs, toll-like receptors; HLA, human leukocyte antigen system; ApoE, apolipoprotein E; Nramp1, natural resistance-associated macrophage protein one; CTLA-4, cytotoxic T lymphocyte antigen-4; DHCR7, 7-dehydrocholesterol reductase; MMPs, matrix metalloproteinases; ROS, reactive oxygen species; PGs, prostaglandins; BMP7, bone morphogenetic protein 7; TGF- $\beta$, transforming growth factor- $\beta$; TIMPs, tissue inhibitor metalloproteinases

gene family, homologous to albumin and a-fetoprotein [5]. $25(\mathrm{OH}) \mathrm{D}$ is transported to the kidney where it is again enzymatically hydroxylated to form $1,25(\mathrm{OH}) \mathrm{D}_{3}$ or calcitriol, the active form of vitamin $\mathrm{D}_{3}$. CYP27B1 is the enzyme responsible for $1^{\alpha}$-hydroxylation in the proximal tubule of the kidney. The production of calcitriol is regulated by rising serum calcium and phosphorus levels [4]. 1,25(OH)D is also highly bound to DBP and this complex activates the vitamin D receptor (VDR). VDR is expressed in many human tissues, such as liver, gastrointestinal tract, pancreas and immune cells (e.g. T lymphocytes, B lymphocytes, natural killer cells). VDR regulates the expression of more than 200 genes and, thus, influences cell proliferation, differentiation, apoptosis, immunomodulation and angiogenesis [7] (Fig. 1).

\section{Vitamin D deficiency}

Vitamin D insufficiency and deficiency are considered to be common in the general population and more frequent among elderly people and individuals with chronic diseases. It has been reported that 1 billion people have inadequate serum levels of $25(\mathrm{OH}) \mathrm{D}$ levels [8]. However, the normal range of vitamin D levels has been debated [9]. In general, optimal vitamin D status ranges from 30 to $50 \mathrm{ng} / \mathrm{mL}$ (i.e. $75-125 \mathrm{nmol} / \mathrm{L}$ ) [10,11]. Vitamin D deficiency has been defined as serum 25(OH)D levels lower than $20 \mathrm{ng} / \mathrm{mL}$ (i.e. $50 \mathrm{nmol} / \mathrm{L}$ ) and vitamin $\mathrm{D}$ insufficiency has been defined as serum levels between 20 and $30 \mathrm{ng} / \mathrm{mL}$ (i.e. $50-75 \mathrm{nmol} / \mathrm{L}$ ) [5,12-14]. According to the Institute of Medicine (IOM) of the National Academies 
in the United States, vitamin D concentration of $20 \mathrm{ng} / \mathrm{mL}$ is adequate [15]. However, the Endocrine Society (Maryland, USA) [16] recommends levels of at least $30 \mathrm{ng} / \mathrm{mL}$ (i.e. $75 \mathrm{nmol} / \mathrm{L}$ ) as adequate and concentrations between 40 and $60 \mathrm{ng} / \mathrm{mL}$ (i.e. $100-150 \mathrm{nmol} / \mathrm{L}$ ) as optimal. There is still no definition regarding the optimal vitamin $\mathrm{D}$ levels for patients with chronic liver diseases.

\section{Vitamin D and chronic liver disease}

Vitamin D has an important role in various chronic diseases, such as infectious and cardiovascular diseases, diabetes mellitus and some types of cancer [17]. In addition, vitamin $\mathrm{D}$ has been associated with chronic liver diseases and it has been reported that low vitamin D status is a common feature in different types of liver diseases $[18,19]$.

According to recent studies, the prevalence of vitamin D insufficiency and deficiency is higher in patients with chronic liver disease than in general population ranging between 64 and $92 \%[20,21]$. It has been also reported that the incidence of vitamin $\mathrm{D}$ deficiency increases as the liver disease progresses [20,21]. In a study by Fisher et al, vitamin D deficiency was higher in cirrhotic patients in Child-Pugh class C than in patients in Child-Pugh class A [21]. Similar results were demonstrated from studies that evaluated vitamin D levels in patients with NAFLD and non-alcoholic steatohepatitis (NASH) [22,23]. According to Barchetta et al [23], patients with NAFLD had lower 25(OH)D than controls (14.8 \pm 9.2 versus $20.5 \pm 9.7 \mathrm{ng} / \mathrm{mL}$ ).

As summarized by Stokes et al, a variety of mechanisms contribute to vitamin D deficiency [9]. In chronic liver diseases, the decreased vitamin $\mathrm{D}$ levels are associated with both malnutrition and low exposure to sunlight. Moreover, liver disease is characterized by low intestinal absorption of vitamin D and low levels of binding proteins (DBP and albumin), which can transfer the hormone to the liver and kidney, in order to be activated. In addition, hepatic hydroxylation of vitamin D is impaired leading to low production of the active hormone, whereas the catabolism of the vitamin is increased [9].

\section{Vitamin D and hepatitis C virus (HCV) infection}

The majority of patients with chronic hepatitis $\mathrm{C}$ have vitamin D deficiency compared to controls (serum $25(\mathrm{OH}) \mathrm{D}$, $25.07 \mathrm{mg} / \mathrm{L}$ versus $43.06 \mathrm{mg} / \mathrm{L}$ ) [24]. According to a cohort study including 468 patients, low serum vitamin $\mathrm{D}$ levels at baseline were associated with failure to achieve sustained virological response (SVR) in HCV genotypes 1, 2, and 3 following treatment with pegylated interferon and ribavirin [25]. Other studies showed that patients with chronic HCV infection (genotypes 1,2/3) using oral vitamin D supplements had higher response to therapy and lower relapse rates [26,27]. Data from in vitro studies supported the significance of vitamin $\mathrm{D}$ in chronic hepatitis $\mathrm{C}$, suggesting $25(\mathrm{OH}) \mathrm{D}$ as a suppressive factor of HCV replication [28,29]. Vitamin D ameliorates the necroinflammatory process and inhibits liver fibrosis, and subsequently, its deficiency could contribute to the progression of chronic hepatitis [24,25].

\section{NAFLD}

NAFLD is the most common chronic liver disorder in economically developed countries, and its prevalence is strongly linked to current lifestyle. Approximately 30\% of patients with NAFLD have NASH in liver biopsy which might progress to liver cirrhosis [30]. Insulin resistance, a component of metabolic syndrome, is implicated in the progression to NASH [31]. Vitamin D has a great impact on $\mathrm{NASH}$, considering that an optimal vitamin D status reduces the incidence of metabolic syndrome [32]. 25(OH)D improves insulin resistance by accelerating the metabolism of proinsulin to insulin $[33,34]$. According to Targher et al, vitamin D deficiency is implicated in steatosis, necroinflammation and liver fibrosis, regardless of other aspects of metabolic syndrome [22]. Nakano et al, using a rat model, examined the role of vitamin D produced by phototherapy on the progression of NASH. Phototherapy reduced inflammation and fibrosis of hepatic cells compared to controls. It has been also suggested that phototherapy improves insulin resistance and inhibits the expression of profibrotic factors, such as transforming growth factor (TGF)- $\beta$ [35].

\section{Vitamin D and liver transplantation}

Vitamin D has immunomodulatory effects with direct actions at dendritic cells, monocytes, macrophages, B-cell, and T-cell functions. Considering that vitamin D and VDR are expressed by several cellular populations of the immune system, such as Th1 and Th2, it has been suggested that calcitriol has a significant role in liver transplantation [2]. Trautwein et al studied 193 patients before and after liver transplantation and concluded that liver transplantation improved serum vitamin D levels and enhanced bone metabolism [36]. Another study suggested that patients with pre-transplant low serum $25(\mathrm{OH}) \mathrm{D}$ levels $(<12.5 \mathrm{ng} / \mathrm{mL})$, were more likely to have organ rejection [37].

\section{Vitamin D and primary biliary cholangitis (PBC)}

PBC is an autoimmune liver disease of unknown etiology. It is characterized by a T-lymphocyte-mediated slowly progressive destruction of small intralobular bile ducts, which results in cholestasis and, eventually, in cirrhosis and liver failure. Vitamin $\mathrm{D}$ has been implicated into the pathogenesis of $\mathrm{PBC}$ [38] through several cell signaling mechanisms namely matrix metalloproteinases, reactive oxygen species, 
prostaglandins, and TGF- $\beta$ in which vitamin D normally plays a regulatory role (of varying degree) [38]. Genetic studies have yielded interesting results on identifying genes that confer susceptibility to PBC. A firm association between PBC and several genes within the major histocompatibility class II region (MHC) has now been reported $[39,40]$.

VDR has been a topic of research in the study of non-MHC genes that link vitamin D to $\mathrm{PBC}$ pathogenesis. Three recent metaanalyses on VDR polymorphisms have provided slightly diverse results [41-43] (Table 1). A number of other genetic factors, namely Toll-like receptors (TLRs), apolipoprotein E (ApoE), Nramp1, and Cytotoxic T lymphocyte antigen-4 (CTLA-4) have also been associated with vitamin D and PBC [38].

Low serum levels of vitamin D have been reported in $\mathrm{PBC}$ patients $[38,44]$ especially compared to controls (significantly lower mean values) $[38,45,46]$. According to Agmon-Levin et al [45], vitamin D deficiency is highly prevalent in the PBC group with almost one third of these patients exhibiting serum vitamin D levels below $10 \mathrm{ng} / \mathrm{mL}$. Treatment with ursodeoxycholic acid (UDCA) resulted in increased levels of vitamin D. An inverse correlation between vitamin D levels and advanced liver disease/histological stage $[45,47]$ has been reported; the authors have commented on the potential use of this finding as a prognostic marker (disease severity, mortality, need for liver transplantation). The same authors also suggest an inverse association between vitamin $\mathrm{D}$ levels and both the markers of PBC disease activity, (namely alkaline phosphatase and bilirubin) [38,47], and the presence of an additional autoimmune disease [38]. PBC patients who failed to respond to UDCA therapy (according to Paris-I/Barcelona criteria) had significantly lower baseline vitamin D levels [47]. Thus, Guo et al suggest a link between pre-treatment vitamin D levels and the response to treatment, irrespectively of the stage of the disease [47]. In addition, Agmon-Levin et al suggest that low vitamin D levels also correlate with the absence of UDCA therapy (among other factors like advanced liver disease and autoimmune comorbidity) [45].

\section{Vitamin D and autoimmune hepatitis (AIH)/primary sclerosing cholangitis (PSC)}

AIH is a chronic inflammatory disease of the liver of unknown etiology. Liver cirrhosis/failure is a possible outcome if left untreated. AIH diagnosis is based on serological, immunological and histopathological findings, namely hyperglobulinemia, circulating autoantibodies and evidence of interface hepatitis on liver biopsy [48]. Patients with AIH have significantly lower vitamin D levels compared with controls $[49,50]$. Several studies have reported a link between genetic factors and pathogenetic mechanisms of AIH. It has been suggested that a number of genes inside the $\mathrm{MHC}$ region confer susceptibility to AIH. Other (non-MHC) vitamin D-related genetic factors include: VDR polymorphisms, CTLA-4, TLRs, cytochrome P450 Cyp2D6, regulatory $\mathrm{T}$ cells, and the forkhead/winged helix transcription factor 3, but data on these factors is limited [50]. Efe et al link low 25(OH)D levels in AIH to advanced fibrosis and severe inflammation [49], whereas at the same time Luong et al suggest that vitamin D may have a beneficial role on AIH [50], and predict response to treatment [49].

The literature on the connection of vitamin D with PSC is scarce. Vitamin D deficiency has been reported in PSC patients which is far exaggerated in the pre-transplantation setting [51]. Very recently it has been reported that CD28- T cells accumulate near the bile ducts of PSC patients, thus promoting inflammation in a tumor necrosis factor- $\alpha$-rich microenvironment. The authors suggest that vitamin D reverses this condition in vitro [52].

\section{Vitamin D and liver cirrhosis}

The deranged metabolism of vitamin $\mathrm{D}$ in liver cirrhosis was first reported in the late '70s [53-55] and it was mainly attributed to impaired 25( $\mathrm{OH})$-vitamin D hydroxylation of the precursor vitamin D due to insufficient liver function $[53,55]$. Before the year 2000, the majority of the studies on vitamin D in cirrhosis [56-58] focused on the association of hepatic insufficiency with bone demineralization, osteomalacia, osteoporosis, minerals metabolism/equilibrium (calcium, phosphorus), possible endocrine disturbances (parathormone - secondary hyperparathyroidism) and, in general, with the homeostasis involving the liver-kidney-gut-calcium axis. In the past two decades, there have been considerable advances in the understanding of the pathophysiology of vitamin D and its possible clinical implications in chronic liver diseases [59-65].

\section{Serum levels of vitamin D in patients with liver cirrhosis}

Vitamin D deficiency in cirrhosis is related to liver dysfunction rather than etiology and it is no longer considered

Table 1 Recent meta-analysis studies on the association of the most well studied vitamin D receptor polymorphisms (BsmI, ApaI, and TaqI) and the risk of primary biliary cholangitis. Overall refers to overall analysis, whereas subgroup refers to subgroup analysis based on ethnicity. Negative reveals no association while positive confirms an association; the degree (significant/non-significant) of association is commented in brackets

\begin{tabular}{lllllll} 
& BsmI overall & BsmI subgroup & ApaI overall & ApaI subgroup & TaqI overall & TaqI subgroup \\
\hline Fang et $a l, 2015[43]$ & Negative & Negative & Positive (significant) & Asian (significant) & Negative & Caucasian \\
Mo et al, $2014[42]$ & Negative & Negative & Negative & Negative & Negative & Negative \\
Li et al, $2014[41]$ & Negative & & Negative & & Positive \\
\hline
\end{tabular}


prevalent only in cholestatic disorders [19,66]. Malham et al [19] compared vitamin D status between patients with alcoholic cirrhosis (ALC) and PBC. ALC patients had lower vitamin D levels compared to PBC patients. A number of studies have supported the prevalence of hypovitaminosis D in chronic liver disease and cirrhosis [67-76] with one study [77] reporting a low prevalence of $25(\mathrm{OH}) \mathrm{D}$ deficiency in a cohort of patients with genotype 1 chronic HCV infection and compensated liver disease ( $15 \%$ cirrhotic patients): $48 \%$ and $16 \%$ of the cohort had vitamin levels of $<75 \mathrm{nmol} / \mathrm{L}$ and $<50 \mathrm{nmol} / \mathrm{L}$, respectively (Table 2).

\section{Relationship between vitamin $D$ and liver fibrosis}

An association of low 25(OH)D levels with advanced fibrosis has been reported in both HCV mono-infected [24] and HCV-HIV co-infected cohorts [67]. In the latter study [67], a significant correlation of $25(\mathrm{OH}) \mathrm{D}$ levels with the histological METAVIR fibrosis score was observed. Two recent genetic studies have further supported the relation between vitamin D and fibrosis. Baur et al [78] studied both 25(OH)D serum levels and VDR gene (NR1I1) polymorphisms in a cohort of patients with chronic hepatitis $C$. The authors concluded that both deficient 25OHD levels and presence of an unfavorable bat - haplotype (bAt[CCA]-haplotype, ApaI rs7975232 CC genotype) increased the risk for fibrosis progression. Likewise, Grunhage et al [79] conducted a large-scale (712 patients) study of genetic variants affecting serum $25(\mathrm{OH}) \mathrm{D}$ levels in chronic liver disease (6.6\% F3 and 57\% F4 patients). Serum levels of $25(\mathrm{OH}) \mathrm{D}$ inversely correlated with transient elastography and fibrosis stages. Homozygous carriers of the rare DHCR7 allele or the common CYP2R1 allele had reduced 25(OH)vitamin D levels. The variant rs12785878 in the DHCR7 locus was correlated with liver stiffness in transient elastography. Their results imply that vitamin $\mathrm{D}$ has a greater impact on the initiation than on the progression of liver fibrosis. Petta et al [80] studied the association between liver fibrosis and certain genetic variants affecting $25(\mathrm{OH}) \mathrm{D}$ serum levels, in a cohort of 260 biopsy-proven genotype 1 chronic HCV-infected patients (17.3\% F3, 11.2\% F4 fibrosis). DHCR7 GG genotype was identified as an independent risk factor for severe fibrosis and was associated with lower vitamin D serum levels. In a recent meta-analysis by Garcia - Alvarez et al [76], a significant association between vitamin D status and liver fibrosis [cut-

Table 2 Studies evaluating Vitamin D levels in patients with chronic liver disease and/or cirrhosis

\begin{tabular}{|c|c|c|c|c|c|c|}
\hline Author [ref] & $\begin{array}{c}\text { Year } \\
\text { (publication) }\end{array}$ & $\begin{array}{l}\text { Etiology of liver } \\
\text { disease }\end{array}$ & $\begin{array}{l}\text { Study } \\
\text { population } \\
\text { (n) }\end{array}$ & $\begin{array}{l}\text { Proportion of } \\
\text { cirrhotics/ALF } \\
\text { patients included }\end{array}$ & $\begin{array}{l}\text { Study in favor of } \\
\text { hypovitaminosis }\end{array}$ & Vitamin D levels \\
\hline Terrier et al [67] & 2011 & HIV-HCV & 189 & $\begin{array}{l}25 \% \text { F3-F4 } \\
0 \% \text { F0 }\end{array}$ & Yes & $\begin{array}{l}\text { F3/F4: } 16.2 \pm 10.0 \mathrm{ng} / \mathrm{mL} \\
\text { F2: } 18.9 \pm 8.5 \mathrm{ng} / \mathrm{mL} \\
\text { F1: } 20.9 \pm 11.1 \mathrm{ng} / \mathrm{mL}\end{array}$ \\
\hline Bitetto et al [69] & 2011 & $\mathrm{HCV}$ & 211 & $\begin{array}{l}\text { Decompensated } \\
\text { disease excluded, } \\
\text { baseline staging: } \\
2 \text { (0-6 Ishak stage) }\end{array}$ & Yes & $\begin{array}{l}\text { Median: } 20.7 \mathrm{ng} / \mathrm{mL}(2.1-59.6) \\
46.4 \%<20 \mathrm{ng} / \mathrm{mL} ; \\
16.1 \%<10 \mathrm{ng} / \mathrm{mL}\end{array}$ \\
\hline Venu et al [71] & 2013 & $\begin{array}{l}\text { Various, mainly } \\
\text { alcohol and HCV }\end{array}$ & 63 & $\begin{array}{l}\text { Liver transplant } \\
\text { candidates }\end{array}$ & Yes & $\begin{array}{l}75 \%<20 \mathrm{ng} / \mathrm{mL} \\
6.3 \%<10 \mathrm{ng} / \mathrm{mL}\end{array}$ \\
\hline Stokes et al [72] & 2014 & $\begin{array}{l}\text { Various, mainly } \\
\text { alcohol }(66 \%)\end{array}$ & 65 & $\begin{array}{l}100 \% \text { cirrhosis, } \\
82 \% \text { with } \\
\text { advanced disease } \\
\text { (CP: B,C stage) }\end{array}$ & Yes & Median: 8.2 ng/mL (4.0-95.8) \\
\hline Anty et al [73] & 2014 & $\begin{array}{l}\text { Various, mainly } \\
\text { alcohol }(71 \%)\end{array}$ & 88 & $\begin{array}{l}100 \% \text { cirrhosis, } \\
\text { with active } \\
\text { infection }\end{array}$ & Yes & Median: $8.8(5.3-14.1) \mathrm{ng} / \mathrm{mL}$ \\
\hline Savic et al [74] & 2014 & Alcohol & 30 & $100 \%$ cirrhosis & Yes & $66.7 \%<50 \mathrm{ng} / \mathrm{mL}$ \\
\hline Finkelmeier et al [75] & 2014 & $\begin{array}{l}\text { Various, mainly } \\
\text { alcohol and HCV }\end{array}$ & 200 & HCC & Yes & Mean: $17 \pm 13 \mathrm{ng} / \mathrm{mL}(1-72)$ \\
\hline
\end{tabular}

ALF, advanced liver fibrosis; CP, Child-Pugh stage; HCC, hepatocellular carcinoma 
offs of $10 \mathrm{ng} / \mathrm{mL}$ (odds ratio, OR: $2.37,95 \% \mathrm{CI}: 1.20-4.72$ ) and $30 \mathrm{ng} / \mathrm{mL}$ (OR: 2.22, 95\% CI: 1.24-3.97)] was observed.

However, two studies $[69,70]$, similar to the study by Kitson et al [77], challenged the results of the earlier studies regarding the relation of vitamin $\mathrm{D}$ with the stage of liver fibrosis. The authors found no association between the baseline $25(\mathrm{OH}) \mathrm{D}$ levels and either the SVR rate or the fibrosis stage. They reported that season, race and geographic latitude were independent predictors of 25(OH)D status. Mean 25(OH)D levels did not significantly vary between fibrosis stages (F0-F4). This discrepancy compared to other studies might be partly related to the lack of certain clinical and laboratory baseline factors (namely season of baseline blood sampling) and to the use of non-standardized commercially available automated assays to measure $25(\mathrm{OH}) \mathrm{D}$ levels. Fig. 1 summarizes main environmental/genetic factors that implicate vitamin $\mathrm{D}$ in the inflammatory/fibrogenetic process.

\section{Prognosis/mortality/infectious complications}

Bankuti et al [68] reported a significant association of $25(\mathrm{OH}) \mathrm{D}$ with the degree of liver dysfunction. They enrolled 75 patients with liver cirrhosis (various etiologies and severity; approximately $14 \%$ of the patients had Child-Pugh C cirrhosis). All patients were followed-up until hepatic decompensation or death. 25(OH)D levels were inversely correlated with MELD score and Child-Pugh score. Patients at the first $(6.9 \pm 1.9 \mathrm{ng} / \mathrm{mL})$ vs. the third/reference $(27.1 \pm 6.3 \mathrm{ng} / \mathrm{mL}) 25(\mathrm{OH}) \mathrm{D}$ tertile had a relative risk for hepatic decompensation and mortality of 6.37 (95\%CI: 1.75-23.2; P=0.005) and 4.31 (95\%CI: 1.38-13.5; $\mathrm{P}=0.012$ ), respectively, after adjustment for age and sex.

Three more studies, two in cirrhotic cohorts [72,73] and another one in patients with hepatocellular carcinoma [75], reached similar conclusions. In the first study, the authors studied the association of vitamin D deficiency with survival in a cohort of 92 patients with advanced liver cirrhosis (82\% Child-Pugh stages B and C) [72]. They reported a considerable incidence of vitamin D deficiency (86\%). In the univariate analysis, low vitamin D levels were associated with mortality; levels $\leq 6 \mathrm{ng} / \mathrm{mL}$ were associated with an unfavorable outcome, whereas vitamin D levels $<20 \mathrm{ng} / \mathrm{mL}$ were not found significant. Multivariate analysis confirmed that both MELD score and serum vitamin $\mathrm{D} \leq 6 \mathrm{ng} / \mathrm{mL}$ were independent predictors for mortality. 25(OH)D levels $\leq 6 \mathrm{ng} / \mathrm{mL}$ had a positive predictive value of $50 \%$ mortality within 24 months. Moreover, mortality from infectious complications was more frequent in this subgroup. The second study was conducted in a cohort of hospitalized cirrhotics of various etiologies [73]. Almost $60 \%$ of the patients had severe vitamin D deficiency $(<10 \mathrm{ng} / \mathrm{mL})$. The authors found an inverse correlation of 25(OH)D levels with the Child-Pugh score, but no correlation with the MELD score. Infections were more frequent in patients with severe vitamin D deficiency compared to nondeficient patients (54 vs. $29 \%$ ). In addition, severe vitamin D deficiency was independently associated with infections together with the Child-Pugh score and the C-reactive protein levels. In the multivariate Cox regression analysis including Child-Pugh score, infections and severe vitamin D deficiency, only the presence of infection was associated with mortality. Lastly, Finkelmeier et al prospectively evaluated the role of serum vitamin D status as a prognostic marker in 200 patients with hepatocellular carcinoma [75]. The authors reported that 25(OH)D3 levels negatively correlated with both the stage of cirrhosis and the stage of hepatocellular carcinoma. Patients with severe $25(\mathrm{OH}) \mathrm{D} 3$ deficiency had the highest mortality risk. In the multivariate analysis, very low 25(OH)D3 levels were independently associated with mortality together with MELD score and high $\alpha$-fetoprotein levels (>400 ng/mL). The authors concluded that $25(\mathrm{OH}) \mathrm{D} 3$ deficiency was associated with advanced stages of hepatocellular carcinoma and was also a prognostic indicator of poor outcome.

\section{SVR in patients with cirrhosis and chronic hepatitis C}

The data in the literature regarding the virological response of antiviral treatment combined with Vitamin D supplementation in patients with liver cirrhosis are scarce. Most of the published data concern patients with chronic hepatitis $\mathrm{C}$ treated with interferon-ribavirin regimens with a small number of cirrhotic patients (usually with compensated disease, ChildPugh class A) [24,67]. As mentioned before, Petta et al [24] reported evidence supporting that low $25(\mathrm{OH}) \mathrm{D}$ levels are an independent risk factor for SVR (interferon-based therapeutic regiments). On the contrary, data from both the HIV-HCV co-infected cohort of Terrier et al [67] and the HCV monoinfected cohort of Kitson et al [77], showed no association between the baseline 25(OH)D status and SVR.

There are two recent meta-analyses in this field [76,81]. The first one reported a high prevalence of vitamin D deficiency and higher likelihood of SVR in the individuals with higher serum vitamin D levels and the individuals on vitamin D supplementation [81]. The second meta-analysis [76] reported a significant association with SVR only for a vitamin D cut-off of $20 \mathrm{ng} / \mathrm{mL}$ (OR: 0.53, 95\% CI: 0.31-0.91). When the outliers were excluded, significant pooled ORs were observed for all patients included [10 ng/mL (OR: 0.48, 95\% CI: 0.34-0.67), $20 \mathrm{ng} / \mathrm{mL}$ (OR: $0.58,95 \%$ CI: 0.45-0.76)] and specifically for genotype $1 / 4$ patients [ $10 \mathrm{ng} / \mathrm{mL}$ (OR: 0.53 , 95\% CI: 0.34-0.81), $20 \mathrm{ng} / \mathrm{mL}$ (OR: 0.54, 95\% CI: 0.39-0.74)].

\section{Clinical implications of vitamin D in the cirrhotic setting}

Several clinical applications of 25(OH)D levels have been suggested, including its use as a non-invasive marker of liver fibrosis in chronic hepatitis C [24], as a prognostic predictive factor for mortality and infections in patients with liver cirrhosis [73] and as a marker of unfavorable outcome and advanced disease stage in patients with hepatocellular carcinoma [75]. Malham et al [19] emphasized the importance 
of monitoring vitamin D in all cirrhotic populations, especially those with alcoholic liver cirrhosis, and commented on the efficacy of treatment in liver insufficiency-associated bone disease, on the possible extraskeletal benefits (muscle function, cancer risk, and immune impairment) and on the probable benefit of higher than standard doses of vitamin D supplementation for repletion. Garcia-Alvarez et al [76] also recommended vitamin D screening in HCV patients. Finkelmeier et al [75] showed that, in patients with hepatocellular carcinoma and vitamin D supplementation, the mean serum $25(\mathrm{OH}) \mathrm{D}$ levels did not differ significantly from those that did not receive supplementation. However, because of the small number of treated patients, these results should be interpreted with caution.

The possible benefit of vitamin D substitution, as a preventive measure for the development of liver fibrosis in patients with chronic hepatitis $\mathrm{C}$, has also been suggested [78]. The same authors comment on expanding the indications for vitamin D supplementation to all patients with chronic liver diseases irrespective of the presence of bone disease. A recent meta-analysis suggested the cutoff of $30 \mathrm{ng} / \mathrm{mL}$ as an appropriate threshold to prevent both fibrosis and treatment failure in patients with chronic hepatitis C [76]. Another study suggested vitamin D supplementation as a preventive, early treatment, strategy against fibrosis in the cohort of HCVinfected patients [82]. Lastly, Lim et al [66] suggested periodic monitoring of 25(OH)D in patients with chronic liver disease and cirrhosis, and substitution therapy in those with levels $<30 \mathrm{ng} / \mathrm{mL}$, which includes administration of $5000 \mathrm{IU}$ of vitamin D3 daily or 50000 IU of vitamin D2 or D3 weekly for 3 months, followed by 1000 IU/day indefinitely.

The Endocrine Society Clinical Practice Guideline (ESCPG) [16] recommend screening for vitamin D deficiency (cutoff $<20 \mathrm{ng} / \mathrm{mL}$ ) in individuals at high risk for deficiency, including those with hepatic failure, and recommends vitamin D supplementation in cases of deficiency. They also suggest that vitamin D requirements may be greater for sick patients than for healthy individuals and that serum vitamin $\mathrm{D}$ levels above $30 \mathrm{ng} / \mathrm{mL}$ may have additional benefits in reducing the risk for various disease conditions. They recommend that all adults who are vitamin D deficient to be treated with $50000 \mathrm{IU}$ of vitamin D2 or vitamin D3 once a week for 8 weeks or its equivalent of $6000 \mathrm{IU}$ of vitamin D2 or vitamin D3 daily to achieve a serum level of $25(\mathrm{OH}) \mathrm{D}$ above $30 \mathrm{ng} / \mathrm{mL}$, followed by maintenance therapy of 1500-2000 IU/day. Furthermore, they have set minimal daily dietary recommendations of vitamin D intake for patients at high risk for vitamin D deficiency, depending on their age group. The extent of the recommended screening indications is limited to hepatic failure and does not cover the full spectrum of liver diseases.

International liver study associations (both EASL [83] and AASLD [84]) recommend fat-soluble vitamin substitution for the management of all patients with cholestatic liver diseases. These recommendations focus mostly on the prevention of osteoporosis. More specifically, they propose clinical assessment of the risk of osteoporosis for all cholestatic patients and emphasize the importance of both identifying reversible risk factors and applying appropriate lifestyle changes. It is highlighted that the risk of osteoporosis is increased in decompensated disease and in high degree of cholestasis and it is suggested at least annual screening intervals following diagnosis. Finally, it is recommended that calcium and vitamin $\mathrm{D}$ supplementation should be considered in all cholestatic disease patients [83].

\section{Discussion}

Vitamin D has an emerging role on immunity, cancer, infectious diseases, fibrosis and chronic liver diseases [85]. The pleiotropic effects of this hormone including the regulation of transcription of over 200 genes involved in cell proliferation and differentiation, immunomodulation, inflammation and fibrogenesis and their effects on liver disease have been extensively reviewed in the literature $[3,24,85]$. Han et al [85] suggested two separate pools of $1,25(\mathrm{OH}) 2 \mathrm{D} 3$ with distinct purposes. The first pool, consisting of the traditional liverkidney loop, facilitates intestinal absorption of calcium by mediating active calcium transport (calbindin) across the intestinal mucosa, which maintains calcium homeostasis in blood and allows for bone calcium deposition (Fig. 1). The second pool involves the immune system and the local production of calcitriol by immune cells (monocytes, macrophages, dendritic, B and $\mathrm{T}$ cells and lymphocytes), which could contribute to immune regulation (with a possible protective role against infections). These separate pools, although not well defined, could contribute to two separate, in essence endocrine and paracrine, homeostasis functions. Our current understanding of vitamin D pathophysiology with regard to liver diseases/cirrhosis is probably best summarized by Petta et al: "a complex interplay between liver damage, vitamin $\mathrm{D}$ and genetic determinants of vitamin $\mathrm{D}$ deficiency" [80].

The majority of the studies on patients with cirrhosis [19,68,71-74] confirm the prevalence of vitamin D deficiency in this setting. The question of whether liver damage precipitates the disturbance in vitamin $\mathrm{D}$ homeostasis or the other way around, still remains, leading to a type of "chicken or the egg" causality dilemma. However, whatever its role in liver disease (epiphenomenon of cirrhosis or co-factor of liver fibrosis and necroinflammation), vitamin D must still be considered as a diagnostic tool and prognostic index.

There is ongoing evidence supporting the importance of vitamin D status on mortality not only in the general population but also in patients with chronic liver diseases, cirrhosis and hepatocellular carcinoma [72-75]. Furthermore, the association of low vitamin D levels with liver insufficiency and infections [72,73] supports the use of vitamin D as a prognostic marker in the population of cirrhotics.

The role of vitamin D supplementation on the achievement of SVR in patients with chronic hepatitis C treated with interferon-based treatment is debatable $[76,77]$. This needs to be elucidated as most published studies included patients with well-preserved liver function and minor fibrosis. However, in the era of direct acting antiviral therapy, the interest in 
vitamin D supplementation for higher SVR rates is expected to decrease together with the declining interferon use.

Current clinical guidelines cover the issue of vitamin D supplementation for bone disease in liver cirrhosis and cholestatic disorders. However, some argue that the established definitions of vitamin D deficiency and insufficiency might not apply in patients with cirrhosis. It is of major importance to define better the details of vitamin D supplementation, such as the threshold for commencing supplementation, optimal duration, other liver-related extra-skeletal indications, dosage customization (maximized dosages in cirrhotics)/optimal level of supplementation), way of delivery and bioavailability, pre-treatment screening intervals, in-treatment efficacy/ monitoring intervals, post-treatment surveillance intervals. Moreover, there are concerns regarding the accuracy of the different $25(\mathrm{OH}) \mathrm{D}$ assays that need to be addressed $[77,86]$.

In conclusion, the association of vitamin $\mathrm{D}$ with liver cirrhosis shows great potential for clinical application. In the near future, we expect a variety of extra-skeletal indications to be explored. The relation between vitamin $\mathrm{D}$ deficiency and the degree of liver function, degree of fibrosis and infectious complications could support its use as a prognostic index and diagnostic tool. The role of vitamin $\mathrm{D}$ in liver cirrhosis needs to be further evaluated and validated in large prospective cohort studies and randomized trials.

\section{References}

1. Holick MF, Garabedian M. Vitamin D: photobiology, metabolism, mechanism of action, and clinical applications. In: Favus MJ (ed). Primer on the metabolic bone diseases and disorders of mineral metabolism. Sixt Edition. Chapter 17. American Society for Bone and Mineral Research; Washington, DC:2006, pp. 129-137.

2. Mahon BD, Wittke A, Weaver V, Cantorna MT. The targets of vitamin $\mathrm{D}$ depend on the differentiation and activation status of CD4 positive T cells. J Cell Biochem 2003;89:922-932.

3. Kitson MT, Roberts SK. D-livering the message: the importance of vitamin D status in chronic liver disease. J Hepatol 2012;57:897-909.

4. Plum L, Deluca H. The functional metabolism and molecular biology of vitamin D action. In: Holick MF (ed.) Vitamin D: Humana Press 2010;61-97.

5. Holick MF. High prevalence of vitamin D inadequacy and implications for health. Mayo Clin Proc 2006;81:353-373.

6. Holick MF. Vitamin D: evolutionary, physiological and health perspectives. Curr Drug Targets 2011;12:4-18.

7. Bouillon R, Carmeliet G, Verlinden L, et al. Vitamin D and human health: lessons from vitamin D receptor null mice. Endocr Rev 2008;29:726-776.

8. Bouillon R. Genetic and environmental determinants of vitamin D status. Lancet 2010;376:148-149.

9. Stokes CS, Volmer DA, Grunhage F, Lammert F. Vitamin D in chronic liver disease. Liver Int 2013;33:338-352.

10. Steingrimsdottir L, Gunnarsson O, Indridason OS, Franzson L, Sigurdsson G. Relationship between serum parathyroid hormone levels, vitamin D sufficiency, and calcium intake. JAMA 2005;294:2336-2341.

11. Chapuy MC, Preziosi P, Maamer M, et al. Prevalence of vitamin D insufficiency in an adult normal population. Osteoporos Int 1997;7:439-443.
12. Bischoff-Ferrari HA, Giovannucci E, Willett WC, Dietrich T, Dawson-Hughes B. Estimation of optimal serum concentrations of 25-hydroxyvitamin D for multiple health outcomes. Am J Clin Nutr 2006;84:18-28.

13. Malabanan A, Veronikis IE, Holick MF. Redefining vitamin D insufficiency. Lancet 1998;351:805-806.

14. Dawson-Hughes B, Heaney RP, Holick MF, Lips P, Meunier PJ, Vieth R. Estimates of optimal vitamin D status. Osteoporos Int 2005;16:713-716.

15. Institute of Medicine Committee to Review Dietary Reference Intakes for Vitamin D, Calcium: The National Academies Collection: Reports funded by National Institutes of Health. In: Ross AC, Taylor CL, Yaktine AL, Del Valle HB, eds. Dietary reference intakes for calcium and vitamin D. Washington (DC): National Academies Press (US) National Academy of Sciences, 2011.

16. Holick MF, Binkley NC, Bischoff-Ferrari HA, et al. Evaluation, treatment, and prevention of vitamin D deficiency: an Endocrine Society clinical practice guideline. J Clin Endocrinol Metab 2011;96:1911-1930.

17. Peterlik M, Cross HS. Vitamin D and calcium deficits predispose for multiple chronic diseases. Eur J Clin Invest 2005;35:290-304.

18. Rode A, Fourlanos S, Nicoll A. Oral vitamin D replacement is effective in chronic liver disease. Gastroenterol Clin Biol 2010;34:618-620.

19. Malham M, Jorgensen SP, Ott P, Agnholt J, Vilstrup H, Borre M, Dahlerup JF. Vitamin D deficiency in cirrhosis relates to liver dysfunction rather than aetiology. World $J$ Gastroenterol 2011;17:922-925.

20. Arteh J, Narra S, Nair S. Prevalence of vitamin D deficiency in chronic liver disease. Dig Dis Sci 2010;55:2624-2628.

21. Heuman DM, Mihas AA, Habib A, et al. MELD-XI: a rational approach to "sickest first" liver transplantation in cirrhotic patients requiring anticoagulant therapy. Liver Transpl 2007;13:30-37.

22. Targher G, Bertolini L, Scala L, et al. Associations between serum 25-hydroxyvitamin D3 concentrations and liver histology in patients with non-alcoholic fatty liver disease. Nutr Metab Cardiovasc Dis 2007;17:517-524.

23. Barchetta I, Angelico F, Del Ben M, et al. Strong association between non alcoholic fatty liver disease (NAFLD) and low 25(OH) vitamin $\mathrm{D}$ levels in an adult population with normal serum liver enzymes. BMC Med 2011;9:85.

24. Petta S, Camma C, Scazzone C, et al. Low vitamin D serum level is related to severe fibrosis and low responsiveness to interferonbased therapy in genotype 1 chronic hepatitis C. Hepatology 2010;51:1158-1167.

25. Lange CM, Bojunga J, Ramos-Lopez E, et al. Vitamin D deficiency and a CYP27B1-1260 promoter polymorphism are associated with chronic hepatitis $\mathrm{C}$ and poor response to interferon-alfa based therapy. J Hepatol 2011;54:887-893.

26. Abu-Mouch S, Fireman Z, Jarchovsky J, Zeina AR, Assy N. Vitamin D supplementation improves sustained virologic response in chronic hepatitis C (genotype 1)-naive patients. World $J$ Gastroenterol 2011;17:5184-5190.

27. Nimer A, Mouch A. Vitamin D improves viral response in hepatitis C genotype 2-3 naive patients. World J Gastroenterol 2012; 18:800-805.

28. Gal-Tanamy M, Bachmetov L, Ravid A, et al. Vitamin D: an innate antiviral agent suppressing hepatitis $\mathrm{C}$ virus in human hepatocytes. Hepatology 2011;54:1570-1579.

29. Matsumura T, Kato T, Tasaka-Fujita M, et al. 25-hydroxyvitamin D inhibits hepatitis $\mathrm{C}$ virus replication and production of the infectious viruses. Hepatology 2011;54:S547A.

30. Williams CD, Stengel J, Asike MI, et al. Prevalence of nonalcoholic fatty liver disease and nonalcoholic steatohepatitis among a largely middle-aged population utilizing ultrasound and liver biopsy: a 
prospective study. Gastroenterology 2011;140:124-131.

31. Ahmed MH, Husain NE, Almobarak AO. Nonalcoholic fatty liver disease and risk of diabetes and cardiovascular disease: what is important for primary care physicians? J Family Med Prim Care 2015;4:45-52.

32. Hypponen E, Boucher BJ, Berry DJ, Power C. 25-hydroxyvitamin D, IGF-1, and metabolic syndrome at 45 years of age: a cross-sectional study in the 1958 British Birth Cohort. Diabetes 2008;57:298-305.

33. Ford ES, Ajani UA, McGuire LC, Liu S. Concentrations of serum vitamin $\mathrm{D}$ and the metabolic syndrome among U.S. adults. Diabetes Care 2005;28:1228-1230.

34. Pittas AG, Lau J, Hu FB, Dawson-Hughes B. The role of vitamin D and calcium in type 2 diabetes. A systematic review and metaanalysis. J Clin Endocrinol Metab 2007;92:2017-2029.

35. Nakano T, Cheng YF, Lai CY, et al. Impact of artificial sunlight therapy on the progress of non-alcoholic fatty liver disease in rats. J Hepatol 2011;55:415-425.

36. Trautwein C, Possienke M, Schlitt HJ, et al. Bone density and metabolism in patients with viral hepatitis and cholestatic liver diseases before and after liver transplantation. Am J Gastroenterol 2000;95:2343-2351.

37. Bitetto D, Fabris C, Falleti E, et al. Vitamin D and the risk of acute allograft rejection following human liver transplantation. Liver Int 2010;30:417-444.

38. KV LN, Nguyen LT. The role of vitamin d in primary biliary cirrhosis: possible genetic and cell signaling mechanisms. Gastroenterol Res Pract 2013;2013:602321.

39. Manns MP, Bremm A, Schneider PM, et al. HLA DRw8 and complement $\mathrm{C} 4$ deficiency as risk factors in primary biliary cirrhosis. Gastroenterology 1991;101:1367-1373.

40. Mella JG, Roschmann E, Maier KP, Volk BA. Association of primary biliary cirrhosis with the allele HLA-DPB $1^{\star} 0301$ in a German population. Hepatology 1995;21:398-402.

41. Li YJ, Tang YW, Shi YQ, et al. Polymorphisms in the vitamin D receptor gene and risk of primary biliary cirrhosis: a meta-analysis. J Gastroenterol Hepatol 2014;29:706-715.

42. Mo C, Lu Y, Deng Y, et al. Lack of association between vitamin D receptor gene ApaI, BsmI, and TaqI polymorphisms and primary biliary cirrhosis risk: a meta-analysis. Tumour Biol 2014;35:49134920.

43. Fang F, Wang J, Pan J, Su GH, Xu LX, Li G. Relationship between vitamin $\mathrm{D}$ (1,25-dihydroxyvitamin D3) receptor gene polymorphisms and primary biliary cirrhosis risk: a meta-analysis. Genet Mol Res 2015;14:981-988.

44. Wagonfeld JB, Nemchausky BA, Bolt M, Horst JV, Boyer JL, Rosenberg IH. Comparison of vitamin D and 25-hydroxyvitamin-D in the therapy of primary biliary cirrhosis. Lancet 1976;2:391-394.

45. Agmon-Levin N, Kopilov R, Selmi C, et al. Vitamin D in primary biliary cirrhosis, a plausible marker of advanced disease. Immunol Res 2015;61:141-146.

46. Reed JS, Meredith SC, Nemchausky BA, Rosenberg IH, Boyer JL. Bone disease in primary biliary cirrhosis: reversal of osteomalacia with oral 25-hydroxyvitamin D. Gastroenterology 1980;78:512-517.

47. Guo GY, Shi YQ, Wang L, et al. Serum vitamin D level is associated with disease severity and response to ursodeoxycholic acid in primary biliary cirrhosis. Aliment Pharmacol Ther 2015;42:221-230.

48. European Association for the Study of the Liver. EASL Clinical Practice Guidelines: Autoimmune hepatitis. J Hepatol 2015;63:971-1004.

49. Efe C, Kav T, Aydin C, et al. Low serum vitamin D levels are associated with severe histological features and poor response to therapy in patients with autoimmune hepatitis. Dig Dis Sci 2014;59:3035-3042.

50. Luong KV, Nguyen LT. The role of vitamin D in autoimmune hepatitis. J Clin Med Res 2013;5:407-415.

51. Jorgensen RA, Lindor KD, Sartin JS, LaRusso NF, Wiesner RH. Serum lipid and fat-soluble vitamin levels in primary sclerosing cholangitis. J Clin Gastroenterol 1995;20:215-219.

52. Liaskou E, Jeffery LE, Trivedi PJ, et al. Loss of CD28 expression by liver-infiltrating $\mathrm{T}$ cells contributes to pathogenesis of primary sclerosing cholangitis. Gastroenterology 2014;147:221-232 e227.

53. Hepner GW, Roginsky M, Moo HF. Abnormal vitamin D metabolism in patients with cirrhosis. Am J Dig Dis 1976;21:527-532.

54. Jung RT, Davie M, Hunter JO, Chalmers TM, Lawson DE. Abnormal vitamin D metabolism in cirrhosis. Gut 1978;19:290-293.

55. Long RG, Skinner RK, Wills MR, Sherlock S. Serum-25-hydroxyvitamin-D in untreated parenchymal and cholestatic liver disease. Lancet 1976;2:650-652.

56. Meyer MS, Wexler S, Jedvab M, Spirer Z, Keysar N, Shibolet S. Low levels of serum calcium, phosphorus and plasma 25-hydroxy vitamin D in cirrhosis of the liver. Isr J Med Sci 1978;14:725-730.

57. Patri B, Le Charpentier Y, Gueris J, Calmettes MC, Dubrisay J. Vitamin D, parathormone, calcitonin and bone histomorphometry in patients with cirrhosis. Rev Rhum Mal Osteoartic 1978;45:631-640.

58. Kanda T, Otsuki M, Akeyama T, et al. The disorder of vitamin D metabolism in patients with liver cirrhosis. Nihon Naibunpi Gakkai Zasshi 1985;61:14-21.

59. Holick MF. Vitamin D: importance in the prevention of cancers, type 1 diabetes, heart disease, and osteoporosis. Am J Clin Nutr 2004;79:362-371.

60. Chiu KC, Chu A, Go VL, Saad MF. Hypovitaminosis D is associated with insulin resistance and beta cell dysfunction. Am J Clin Nutr 2004;79:820-825.

61. Veldman CM, Cantorna MT, DeLuca HF. Expression of 1,25-dihydroxyvitamin D(3) receptor in the immune system. Arch Biochem Biophys 2000;374:334-338.

62. Willheim M, Thien R, Schrattbauer K, et al. Regulatory effects of 1alpha,25-dihydroxyvitamin D3 on the cytokine production of human peripheral blood lymphocytes. J Clin Endocrinol Metab 1999;84:3739-3744.

63. Timms PM, Mannan N, Hitman GA, et al. Circulating MMP9, vitamin D and variation in the TIMP-1 response with VDR genotype: mechanisms for inflammatory damage in chronic disorders? Qjm 2002;95:787-796.

64. Cigolini M, Iagulli MP, Miconi V, Galiotto M, Lombardi S, Targher G. Serum 25-hydroxyvitamin D3 concentrations and prevalence of cardiovascular disease among type 2 diabetic patients. Diabetes Care 2006;29:722-724.

65. Cantorna MT, Zhu Y, Froicu M, Wittke A. Vitamin D status, 1,25-dihydroxyvitamin D3, and the immune system. Am J Clin Nutr 2004;80:1717s-1720s.

66. Lim LY, Chalasani N. Vitamin D deficiency in patients with chronic liver disease and cirrhosis. Curr Gastroenterol Rep 2012;14:67-73.

67. Terrier B, Carrat F, Geri G, et al. Low 25-OH vitamin D serum levels correlate with severe fibrosis in HIV-HCV co-infected patients with chronic hepatitis. J Hepatol 2011;55:756-761.

68. Putz-Bankuti C, Pilz S, Stojakovic T, et al. Association of 25-hydroxyvitamin D levels with liver dysfunction and mortality in chronic liver disease. Liver Int 2012;32:845-851.

69. Bitetto D, Fattovich G, Fabris C, et al. Complementary role of vitamin $\mathrm{D}$ deficiency and the interleukin-28B rs12979860 C/T polymorphism in predicting antiviral response in chronic hepatitis . Hepatology 2011;53:1118-1126.

70. El-Maouche D, Mehta SH, Sutcliffe CG, et al. Vitamin D deficiency and its relation to bone mineral density and liver fibrosis in HIVHCV coinfection. Antivir Ther 2013;18:237-242.

71. Venu M, Martin E, Saeian K, Gawrieh S. High prevalence of vitamin A deficiency and vitamin $\mathrm{D}$ deficiency in patients evaluated for 
liver transplantation. Liver Transpl 2013;19:627-633.

72. Stokes CS, Krawczyk M, Reichel C, Lammert F, Grunhage F. Vitamin D deficiency is associated with mortality in patients with advanced liver cirrhosis. Eur J Clin Invest 2014;44:176-183.

73. Anty R, Tonohouan M, Ferrari-Panaia P, et al. Low Levels of 25-Hydroxy Vitamin D are Independently Associated with the Risk of Bacterial Infection in Cirrhotic Patients. Clin Transl Gastroenterol 2014;5:e56.

74. Savic Z, Damjanov D, Curic N, et al. Vitamin D status, bone metabolism and bone mass in patients with alcoholic liver cirrhosis. Bratisl Lek Listy 2014;115:573-578.

75. Finkelmeier F, Kronenberger B, Koberle V, et al. Severe 25-hydroxyvitamin D deficiency identifies a poor prognosis in patients with hepatocellular carcinoma - a prospective cohort study. Aliment Pharmacol Ther 2014;39:1204-1212.

76. Garcia-Alvarez M, Pineda-Tenor D, Jimenez-Sousa MA, Fernandez-Rodriguez A, Guzman-Fulgencio M, Resino S. Relationship of vitamin D status with advanced liver fibrosis and response to hepatitis $\mathrm{C}$ virus therapy: a meta-analysis. Hepatology 2014;60:1541-1550.

77. Kitson MT, Dore GJ, George J, et al. Vitamin D status does not predict sustained virologic response or fibrosis stage in chronic hepatitis C genotype 1 infection. J Hepatol 2013;58:467-472.

78. Baur K, Mertens JC, Schmitt J, et al. Combined effect of 25-OH vitamin D plasma levels and genetic vitamin D receptor (NR 1I1) variants on fibrosis progression rate in HCV patients. Liver Int 2012;32:635-643.

79. Grunhage F, Hochrath K, Krawczyk M, et al. Common genetic variation in vitamin $\mathrm{D}$ metabolism is associated with liver stiffness. Hepatology 2012;56:1883-1891.

80. Petta S, Grimaudo S, Marco VD, et al. Association of vitamin D serum levels and its common genetic determinants, with severity of liver fibrosis in genotype 1 chronic hepatitis C patients. J Viral Hepat 2013;20:486-493.

81. Villar LM, Del Campo JA, Ranchal I, Lampe E, Romero-Gomez M. Association between vitamin D and hepatitis C virus infection: a meta-analysis. World J Gastroenterol 2013;19:5917-5924.

82. Rahman AH, Branch AD. Vitamin D for your patients with chronic hepatitis C? J Hepatol 2013;58:184-189.

83. EASL Clinical Practice Guidelines: management of cholestatic liver diseases. J Hepatol 2009;51:237-267.

84. Lindor KD, Gershwin ME, Poupon R, et al; American Association for Study of Liver D. Primary biliary cirrhosis. Hepatology 2009;50:291-308.

85. Han YP, Kong M, Zheng S, et al. Vitamin D in liver diseases: from mechanisms to clinical trials. J Gastroenterol Hepatol 2013;28(Suppl 1):49-55.

86. Kitson MT, Button P, Roberts SK. Reply to: Vitamin D status does not predict sustained virologic response or fibrosis stage in chronic hepatitis C genotype 1 infection. J Hepatol 2013;59:194-195. 